\title{
Teniente Remedios Jover CÁNOVAS \\ (Estado MAYor 3 División, XV CUERPo del EJÉrCito del Ebro)
}

\author{
Esther Gutierrez Escoda \\ Universidad Rovira Virgili \\ esther.gutierrez@estudiants.urv.cat
}

Recibido: 25-02-2011

Aceptado: 15-04-2011

\section{Resumen}

Tradicionalmente la historiografía ha dado por sentado que la participación de las mujeres en el Ejército Popular fue momentánea, ya que el Gobierno de la República las excluyó del mismo a finales de 1936. Entendemos que la concepción y mitificación de la "joven miliciana" es otro error historiográfico. El presente artículo analiza el ejemplo de Remedios Jover y el problema psicoafectivo que suscitó entre la tropa del Ejército Popular el hecho de tener en sus filas a mujeres soldado con o sin cargo militar.

Palabras Clave: Guerra Civil, milicias, mujeres, ejército, batalla, exilio, delación.

\begin{abstract}
The historiography traditionally indicates that the participation of women in the Popular Army was momentary, once the Government of the Republic exclude them from it by the end of 1936. "The young militiawoman" is another erroneous conception of the historiography. The present article analyses the example of Remedios Jover and the psychoaffective problem that arose among the Popular Army troops having in its ranks female soldiers with or without military post.
\end{abstract}

Key words: Civil War, militias, women, army, battle, exile, delation. 


\section{Remedios Jover Cánovas “la Casera” (1899-1936)}

Remedios Jover Cánovas nació en Ain-El-Turk (Orán) el 16 de marzo de 1899 en el seno de una familia humilde y comprometida socialmente con el movimiento obrero y con las ideas progresistas de inicios de siglo. Tal circunstancia influirá sin lugar a dudas en su compromiso personal respecto a la defensa de la República y de las clases sociales más desfavorecidas. Sus padres, Ramón Jover y Remedios Cánovas, se habían trasladado a Orán en calidad de mano de obra agrícola temporera y se establecieron en Argelia hasta 1906, año en que la familia regresaría a Novelda (Alicante), su ciudad natal.

Cuando Remedios cuenta siete años de edad (1906), el matrimonio JoverCánovas regresa a Novelda y en 1914 fija su residencia definitiva en la vecina localidad de Petrer para trabajar de caseros en la finca de "La Foia". Por esta razón se les empezó a conocer como Ramón y Remedios "Els Caseros", un apodo que también heredaron sus seis hijos. Posteriormente la familia compra una casa en el Carrer Nou, y Remedios, con los estudios elementales terminados, inicia su vida laboral en la industria textil de Petrer.

Entre los 16 y 22 años, trabaja en la fábrica de lonas de Vicente Castelló y Cía. situada en la Partida de Santa Bárbara, junto al río Vinalopó. En ella más de 300 trabajadores cumplían una jornada laboral de 12 horas ininterrumpidas. La fábrica de lonas donde trabajaba Remedios tuvo una ascensión meteórica puesto que la coyuntura internacional desembocó en la Primera Guerra Mundial, y ello influyó notablemente en la prosperidad de la industria textil española: buena parte de las tiendas de campaña que se utilizaron en este conflicto bélico se fabricaron allí, y muchos barcos fueron equipados con velas procedentes de esta factoría.

Al finalizar la Gran Guerra se produce una fuerte oleada de huelgas en las que participaron Remedios Jover y su madre. En uno de estos conflictos, ambas mujeres -con otras compañeras de la fábrica- evitaron la detención del líder anarcosindicalista Juan Brotons Maestre "Capotillo": le vistieron con ropas femeninas y pudo salir de la factoría inadvertido ante la Guardia Civil (Navarro Poveda, 1997).

Ante las protestas sindicales y las manifestaciones, los patronos decidieron trasladar la fábrica a Novelda en 1921, lo que supuso un gran golpe para la economía de Petrer ya que hubo despidos en masa, entre ellos el de Remedios (Martínez Maestre, 1990). Tras perder su trabajo en la factoría de Santa Bárbara, se 
incorporó a la fábrica de Calzados Luvi como "aparadora". Contaba por aquel entonces 23 años de edad y su capacidad organizadora y de mando eran visibles; al poco tiempo de entrar en esta empresa, consiguió el puesto de encargada de su sección. Esto suponía la responsabilidad del proceso de montaje en cadena, en el que se combinaban las operaciones con máquina y otras a mano. Sin lugar a dudas una tarea minuciosa (Ponce Lorenzo, 1997).

Fue precisamente en esta etapa cuando Remedios conoció al que sería su esposo, Miguel Aracil, natural de Petrer y trabajador de la misma fábrica. Del matrimonio nacerán dos hijos: Miguel y Ramón. En 1931, su esposo desaparece y, en medio a esta situación, ella regresa con los hijos a casa de sus padres en el Carrer Nou de Petrer.

Remedios siempre simpatizó con los movimientos sociales y progresistas, aunque hoy por hoy no podemos adscribirla a ningún sindicato o partido político. El hecho de hacerse cargo de la familia no fue un impedimento para involucrarse en las constantes huelgas que azotaron la zona a inicios de 1936. Con el objetivo de recaudar fondos para los huelguistas, se une a sus vecinos de Petrer y forma el grupo musical al que llamaron "La Estudiantina". Precisamente mientras realizaba una actuación en Banyeres estalló la Guerra Civil (Aracil Jover, 23-11-2009).

La nueva situación bélica y la incapacidad del Gobierno republicano para controlarla hicieron necesario un replanteamiento de las relaciones de género. De este modo, el carácter revolucionario popular junto con la multiplicidad de las ideologías republicanas influyó sin duda en el posicionamiento de muchas mujeres que vieron la posibilidad de una participación igualitaria en el conflicto. Este fue el caso de Remedios Jover. La primera esfera tradicionalmente masculina en la que entró la mujer fue la acción militar, y fueron las mujeres anarquistas y las de la JSU las primeras en ir a luchar al frente (Ruíz Franco, 2000). 


\section{Remedios Jover Cánovas "La Teniente" (1936-1939)}

Figura $1^{1}$

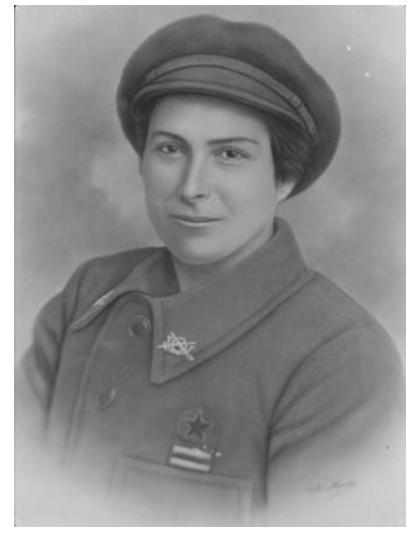

Teniente Remedios Jover Cánovas

El golpe de Estado de los franquistas trastocó no sólo la situación política del país, sino también la vida cotidiana de una población que vivía inmersa en la tradicional distinción de roles sociales entre los dos sexos. Durante las primeras semanas del conflicto bélico muchas mujeres partieron hacia las trincheras, entre ellas Remedios Jover Cánovas (Strobl, 1996). La carrera militar de Remedios dentro del Ejército Popular estaría condicionada por la evolución y reorganización del mismo, ya que el ejército republicano se modificó y reestructuró cuatro veces a lo largo de la Guerra Civil.

Durante la fase miliciana del conflicto, hombres y mujeres - unos obligados por la movilización de las quintas de 1934 y 1935 y otros voluntarios- fueron reclutados en Alicante y partieron hacia diferentes destinos: Guadarrama, Córdoba, Granada y Talavera. El día 15 de septiembre salía hacia Peguerinos la 40 Compañía de Asalto de Alicante (Martínez López, 2007).

Remedios Jover inicia su tarea militar unos días antes que el resto de sus compañeros alicantinos, ya que desde julio de 1936 formaba parte del "Batallón Octubre 11", responsable de la defensa de Madrid. Este batallón, alistado con una organización estrictamente militar, poseía una Compañía de Transporte de Automóvil y su sentimiento de cuerpo era tan intenso que los milicianos se sentían orgullosos de pertenecer a esta unidad. La revista del Batallón, llamada también "Octubre", en la página 2 del mes de agosto hace alusión a la incorporación a filas de Remedios, e incluye las únicas palabras que han quedado escritas de esta excepcional mujer, y que por su significado transcribimos literalmente:

“Magnifico ejemplo! Remedios Jover, mujer del pueblo auténtico se ha incorporado al
Batallón Octubre. Este hecho no tiene más valor que el deseo de machacar al fascismo.
Ahora bien, en las condiciones en que ésta camarada ha venido a luchar contra nuestros
seculares enemigos, si tiene alto valor que demuestra hasta qué punto es un modelo en
el que deben fijarse todas nuestras compañeras. Esta mujer no ha podido entregar el

${ }^{1} 30$ Brigada Mixta, 2 División del Ejército Centro, diciembre de 1936. (Fotografía cedida por Remedios Aracil Alzadora). 
fruto de su vida por cuanto todos los hijos que tiene cuentan con una edad infantil. El mayor de los dos que cobija bajo su hogar cuenta con ocho años. Esto no ha sido un obstáculo: Como no puedo dar mis hijos en defensa de la causa del pueblo, doy mi vida" “... ¡Magnifico ejemplo, camaradas! Su valor es digno de que figure en nuestro Cuadro de Honor" (Navarro Poveda, 1997:30).

El Batallón Octubre 11 se había reclutado entre las JSU (Juventudes Socialistas Unificadas), bajo la dirección y responsabilidad del socialista italiano Fernando de la Rosa. Esta unidad miliciana llegó a tener 16 compañías dentro de la columna SabioRubio, y su núcleo principal fue precisamente el Batallón Octubre 11, así como el Batallón de Aviación del TC Sabio, en la zona del Escorial (Engel, 2005). El 1 de agosto, al anochecer, Remedios Jover partía en tren desde Madrid hacia El Escorial, junto con sus compañeros de milicias. De allí, siguieron en camión hasta Pegueritos y después, a pie, llegaron a San Rafael. Fue entonces cuando el batallón concentró sus fuerzas en un campamento al que denominaron "Las Navazuelas", lugar donde hoy en día se encuentra el Valle de los Caídos. Durante los días siguientes los milicianos exploraron la zona y ocuparon Cabeza Lijar el 6 de agosto sin incidencias destacables. A mediados de mes empezaron los combates de artillería, aunque en esos momentos el frente no era en absoluto continuo. El 15 de septiembre se inició un bombardeo excepcional en la zona, el batallón quedó incomunicado por teléfono y empezó entonces la ofensiva republicana con la intencionalidad de atacar por sorpresa al enemigo.

Manuel Tagüeña anota en sus memorias: "Pronto vimos a Remedios, una alicantina luego ascendida a Alférez, agitando una manta roja, pero fuimos rechazados con grandes bajas" (Tagüeña Lacorte, 2005: 122) Las tropas franquistas se establecieron con firmeza en Cabeza Lijar y pocas horas después moría Fernando de la Rosa, momento en el que se inicia la inmediata retirada de la cima. En esos instantes de incertidumbre Manuel Tagüeña Lacorte asume el mando del batallón (Ibíd., p. 136). Fue en plena retirada, y en dirección hacia abajo, cuando Remedios se dio cuenta de que su compañero de batallón Vicente Aracil Maestre, de 22 años, estaba en el suelo herido. Sin saber en realidad si Vicente estaba vivo o muerto, retrocedió y lo cargó a su espalda, sujetándole por el cuello para repartir el peso del soldado. Inicia entonces el rápido descenso de la cima, pero a los pocos segundos la metralla también alcanza a Remedios que resulta gravemente herida (Aracil Redondo, 17-04-2010).

El intento de salvar a Vicente resultó fallido porque ya estaba muerto cuando nuestra protagonista lo recogió del suelo. Dada la gravedad de las heridas causadas por el impacto de la metralla en su cabeza, a ella también la dieron por muerta. No obstante, el soldado encargado de enterrar a los muertos en la fosa común de las Milicias vio que 
entre éstos había una cabeza que parecía tener el cabello largo. Volteó el cuerpo para ver la cara del soldado y fue entonces cuando pudo comprobar que en realidad se trataba de una mujer y que todavía respiraba (Aracil Jover, 23-11-2009). A continuación fue trasladada al Hospital de El Escorial, mientras sus familiares la creían muerta, pues habían recibido un telegrama comunicando su fallecimiento en combate en el sector de Cabeza Lijar. El Doctor Mezquita Moreno fue quien certificó el parte médico de Remedios. El documento nos indica que, después de ser operada con carácter de urgencia y con un pronóstico gravísimo, Remedios Jover fue evacuada al Cuartel del Batallón Octubre 11, donde sería dada de alta el día 31 de octubre. (Mezquita Moreno, 14-8-1937).

Por esas fechas la Batalla de Madrid inauguraba una nueva forma de hacer la guerra. Esta sería la causa directa de la transformación de los milicianos en soldados propiamente dichos del nuevo ejército. Mientras que la alférez Remedios Jover realizaba la convalecencia, obtenía a la vez el ascenso a Teniente, grado militar que conservará hasta el fin de la guerra, en principio por su comportamiento dentro de las filas milicianas: "interviniendo con arrojo en el combate librado en la posición de Cabeza Lijar" (Tagüeña Lacorte, 31-12-1936).

En esos mismos momentos se iniciaba la formación del futuro Ejército Popular, ya que entre septiembre y octubre del 36 pasaron a escalas activas del Ejército todos los mandos, oficiales y clases de Milicias, que debidamente controladas por la Inspección General, demostraran su capacidad militar y político-social. Además, a partir de estas fechas fue el Estado Mayor del Ministerio de la Guerra el que determinó en qué Armas y Cuerpos debían ser incluidos los nuevos cargos (La Gaceta de Madrid, 1936). De este modo, en diciembre del mismo año, las milicias quedaron asimiladas al Ejército Republicano propiamente dicho y bajo el Código de Justicia Militar. Se creaban entonces tres centros de instrucción en Madrid para los cuadros de mando (entre ellos la Teniente Remedios), donde la enseñanza impartida era eminentemente práctica: deberes generales de mando, armamento, tiro, fortificación, táctica de combate, topografía, enlaces y transmisiones (La Gaceta de la República, 1936).

Con la intención de reducir el número de batallones existentes, éstos y las diversas columnas empezaron a reorganizarse con una enumeración correlativa y sin ningún sobrenombre. Es en este momento cuando el Batallón Octubre 11 pasa a denominarse 30 Brigada Mixta, perteneciente a la $2^{\text {a }}$ División del Ejército Centro.

Según se desprende del certificado emitido por el Comandante Manuel Tagüeña en Madrid (fechado en diciembre del año 1936), Remedios Jover cesó oficialmente en el Ejército a raíz de la exclusión expresa de las mujeres de sus plantillas. 
A pesar de esto, la Teniente continuaría formando parte del mismo hasta el final del conflicto bélico. En mayo de 1937, Remedios era miembro activo del Estado Mayor de la 30 Brigada Mixta (Primer Batallón, Primera Compañía) y continuaba por aquellos días en el sector de Cabeza Lijar en la sierra de Guadarrama.

El hecho de pertenecer al Estado Mayor implicaba formar parte del grupo de oficiales (un capitán y tres tenientes) que cumplían con las tareas de Administración y Logística, siempre bajo el mando de un oficial de rango inmediatamente superior: Mayor, Teniente Coronel o Coronel, ya que con la segunda reforma del Ejército Republicano (febrero de 1937) se habían suprimido varias categorías militares. De este modo, el Estado Mayor asesoraba técnicamente a los militares de rango inmediatamente superior, al tiempo que supervisaba las órdenes impartidas por el responsable último de la Brigada. Cuando el momento lo precisara, estarían en las trincheras a primera línea de fuego junto a los demás soldados. Estas fueron algunas de las tareas que la Teniente Remedios llevó a cabo a lo largo de toda la guerra.

El batallón al que pertenecía la Teniente contaba con una Compañía de Transporte Automóvil, lo que indica que Remedios podía contar con la flota de transporte del Ejército para trasladarse del frente a Petrer y de Petrer al frente. Unas cartas enviadas por Constantino Pascual a sus padres, desde El Escorial (fechadas en junio de 1937), muestran que en dichos viajes la Teniente, además de abastecer a la tropa, realizaba encargos demandados entre los soldados y sus familias:

"El motivo de esta carta es para decirle que con Remedios he mandado unos leguis, una novela y tres paquetes para el padre, también le digo que me mande con Remedios cartas y sobres que ya no me quedan [...]" (Pascual Payá, 22-06-1937).

En estos viajes la Teniente también trasladaba hacia el frente a los muchachos de Petrer que se alistaban como voluntarios en el Ejército Republicano. Faustino Francés, que partió con ella en 1937 hacia El Escorial, nos ofrece su testimonio:

"Tenía mucha amistad con ella y cuando necesitaba a alguien, siempre me decía que me fuera con ella... Remedios estaba en el frente, en las trincheras, pegando tiros como el que más, y de vez en cuando me decía vente para aquí, vente para allá, que tenemos que llevar esto a un sitio [...]" (Francés, 06-05-2010).

Otro de los muchachos que intentó marchar al frente fue Pepe Medina, que entonces contaba tan sólo 15 años. Lo hizo por dos veces pero ante su minoría de edad, la Teniente se opuso de lleno: 
"Me subí al camión sin que ella me viera, pero a la salida de Petrer cuando se dio cuenta de que estaba allí se enfadó y me sacó a la fuerza... La segunda vez que lo intenté lo conseguí, ella no me vio, y llegué hasta Madrid, pero cuando se dio cuenta me mandó de inmediato a Petrer... Éramos vecinos, vivíamos en la misma calle... Tal vez tenía razón Remedios ¿Qué hubieran pensado mis padres? [...]” (Beltrán Medina, 30-112009).

Los sucesivos fracasos en el intento de conquistar Madrid hicieron cambiar la estrategia de Franco, que optó entonces por una guerra larga, de desgaste y aplastamiento gradual del enemigo. Mientras tanto, el Coronel republicano Vicente Rojo Lluch inicia una ofensiva de distracción montada por sorpresa en Brunete con la intención de detener el avance franquista sobre Santander (Casanovas y Gil Andrés, 2010). En julio de 1937, la 30 Brigada Mixta participa en la Batalla de Brunete. Un mes después, cuando Manuel Tagüeña es ascendido a responsable de la Tercera División, el Estado Mayor de la 30 Brigada Mixta (incluida la Teniente Remedios Jover) se integra por completo a la nueva División. El hecho de dejar la 30 Brigada Mixta supuso para los combatientes de la Compañía una gran pérdida. Fernando Verdú, soldado alicantino compañero de la Teniente que moriría poco después en combate, le dedicó una sentida poesía con motivo de su nuevo destino, de la cual podemos evidenciar dos hechos destacables. Por un lado, que Remedios continuaba ejerciendo de militar con grado de teniente, y por otro no menos importante, que desempeñaba y representaba un papel importante entre sus compañeros del frente.

Durante el verano de 1937, la nueva División de la teniente Remedios se dedicó a la organización e instrucción, acantonada en la zona de Madrid. A principios de diciembre del mismo año se creó la División Táctica de Reserva, con el Estado Mayor de la 3 División que incluye ahora las Brigadas Mixtas 33, 27 y 31. Esta nueva División, de la cual formará parte la Teniente, se convierte en Unidad de Choque Especial, por lo que una vez trasladada al frente de Aragón (Villarluengo y Monroyo) será cedida momentáneamente al V Cuerpo del Ejército bajo el mando de Enrique Líster. La Unidad de Choque se acantonará en Monroyo y cubrirá Valderrobles hasta el 31 de mayo de 1938, día en que se produce la retirada hacia Cataluña.

El Jefe del Estado Mayor de la 35 División explica en sus memorias que en Aragón llegó como refuerzo la 3 División, sacada rápidamente de la zona del centro peninsular a petición del General Rojo Lluch con la intención de parar el avance franquista: "El heroísmo desplegado por esta División así como su técnica de combate fue para nosotros una auténtica revelación” (Henríquez Caubín, 1944:5). No obstante, la terrible Batalla de Teruel y la derrota republicana en el río Alfambra desgastaron por completo al Ejército Popular, lo que generó una nueva reestructuración que daría 
nacimiento al Ejército del Ebro, bajo el mando de Modesto Guilloto.

En el Ejército del Ebro se encuadraron dos cuerpos: el V (de Enrique Líster) con las Divisiones 11, 45 y 46; y el XV (de Manuel Tagüeña) con las Divisiones: 3, 35 y 42 (Cuéllar, 2006). El Coronel Modesto Guilloto diseñó el nuevo Ejército aceptando los cargos militares que propuso Manuel Tagüeña para la 3 División. Explica en su obra que el General Vicente Rojo Lluch conocía a todos los mandos, por lo menos hasta brigada, y en muchos casos los jefes de batallón (Modesto Guilloto, 1978). Consecuentemente, la cúpula del Ejército Popular sabía de la existencia de la teniente Remedios, a pesar de la exclusión de las mujeres en el mismo.

La retirada desde Aragón hacia Cataluña llevó a Remedios a la comarca de El Priorat, en la provincia de Tarragona, localizada en el margen izquierdo del río Ebro. La División de la Teniente comprendía el centro del dispositivo del XV Cuerpo del Ejército en la Batalla del Ebro, por lo que fue una de las que más bajas humanas sufrió: cubrió el frente desde el norte de Lérida hasta el mar, siguiendo los cursos de los ríos Segre-Ebro, e implicó a un total de 35.000 soldados.

Del 17 de abril de 1938 hasta finales de diciembre del mismo año, el Estado Mayor de la 3 División (con todos sus servicios) se ubicaba en Escaladei, con lo cual, la comarca de El Priorat se militarizaría por momentos repartiéndose las infraestructuras y logística militar por las diferentes localidades. De este modo, en La Vilella Alta se instalaron tres cocinas de Intendencia donde se guisaba el rancho para luego ser llevado al frente del Ebro. También se instaló el Hospital de Sangre para los heridos leves, las Brigadas Internacionales y las Transmisiones. La gente de esta pequeña localidad mantiene un recuerdo muy vivo de la estancia de la teniente Remedios en la comarca:

"Recuerdo perfectamente el día que estábamos en la cocina (de Intendencia) y realizábamos trueque con los soldados: su pan que estaba florecido, por huevos de nuestras gallinas, vino y fruta fresca $[\ldots]$ Entonces apareció inesperadamente la teniente Remedios por la carretera [...] Y cuando se percató del intercambio que realizábamos con la tropa, saltó del vehículo y se encaró muy enojada con los soldados. La Teniente con los soldados tenía un carácter muy disciplinario, porque como ella misma dijo: ¿Qué estás haciendo? ¡Con el pueblo no se intercambia, al pueblo se le regala la comida! [...]"

“[...] La Teniente dejó aquel día a toda la tropa sin pan. Regaló al pueblo no el pan florecido, sino el blanco de los soldados, el florecido lo hizo tirar por el barranco que da al riachuelo de Escaladei [...] Cuando ella se marchó nosotros fuimos a recogerlo, de este modo tuvimos el pan blanco y el florecido [...] Había un hambre terrible por aquellos días" (Sentís, 20-09-2006).

La población civil de La Vilella Alta, al igual que el resto del país, sufría las carencias derivadas del conflicto bélico, pero mientras estuvo la teniente Remedios en 
El Priorat estas penurias se mitigaron de forma considerable. Así lo recuerdan también algunas mujeres que entonces eran todavía niñas:

\begin{abstract}
"Mira, a la Teniente le gustaba mucho el pan de higo, nosotras, la pandilla de las niñas, de los higos hacíamos pan para la teniente Remedios, entonces íbamos andando hasta Escaladei donde vivía y ella nos daba a cambio ropa de abrigo ya que era invierno y hacía mucho frío [...] Todavía recuerdo hoy en día el jersey de lana de color rosa que me regaló... Íbamos todas las niñas cantando por la carretera: ¡No hay más Remedios que la Teniente!, porque era ella la que nos proporcionaba los suministros y la comida cuando más lo necesitábamos [...]" (Salat, 23-09-2006).
\end{abstract}

Los niños de Escaladei y de La Morera del Montsant también la recuerdan con mucho afecto, José María Ossó nos cuenta que su padre era el cartero del pueblo pero que con la Batalla del Ebro tuvo que marchar al frente. Para no perder la plaza de Correos del padre, José María y su madre recogían la correspondencia en la estafeta de Poboleda y la llevaban al Estado Mayor de la 3 División en Escaladei, por lo que tenían que recorrer unos 15 kilómetros:

\begin{abstract}
"Cuando le subía las cartas, ella siempre me daba algo a cambio... Recuerdo un día que cuando me vio con las cartas en la plaza me dijo: ¡Sube que un Cartero no puede ir así vestido! [...] Me llevó al almacén donde guardaban la ropa y me regaló un traje compuesto por un pantalón, y una americana de color azul marino, también una camisa de color blanco. Si hubiera hecho la Comunión, de bien seguro que no hubiera ido tan elegante... Yo tenía tan sólo 12 años [...] Y recuerdo que cuando se acercaba la Navidad hizo montar a los soldados unas mesas largas en la plaza, las llenó de juguetes de todas clases, y nos dijo: ¡Son regalos para los niños, que se acerquen y que cada cual escoja el que quiera, pero tienen preferencia los más chiquitos, que sean ellos los primeros!... Como que yo ya tenía 12 años fui de los últimos y escogí un dominó de madera de encina, que todavía conservo [...]" (Ossó, 09-06-2010).
\end{abstract}

Los testimonios recuerdan que la Teniente era una persona muy solidaria con el pueblo sobre todo con los niños, pero su carácter era a veces difícil y complicado, al menos por lo que respecta a los soldados: “¡Era muy recta con la tropa, no dejaba pasar ni una, menuda era la Teniente!. Pero mientras ella estuvo aquí, el chusco de pan no le faltó a nadie" (Beltrán, 15-09-2009).

Sisco Porqueres recuerda la llegada de dos camiones cargados uno con uvas y el otro con pastillas de jabón. Uno de los soldados se subió al que iba cargado de jabón y cogió una pastilla sin permiso:

"La Teniente cuando lo vio, lo hizo bajar inmediatamente de malas maneras, lo detuvo y lo metió en la Prisión Militar por ladrón... ¿Quieres decir que por una pastilla de jabón era necesario encarcelarlo?" (Porqueres, 19-05-2010). 
Las personas que conocieron a Remedios en su fase militar, mantienen un recuerdo muy vivo de su personalidad. A todos (civiles y militares) les impactó la presencia de una mujer entrada en edad, madre de dos hijos, soltera (recordemos que su marido salió un día de casa para no volver jamás, sin dejar rastro, mucho antes del inicio de la Guerra Civil), vestida con traje de oficial y luciendo los galones del Ejército Popular; siempre con la pistola colgada de su cinturón, vistiendo pantalones y con pelo corto, dando órdenes al resto de la tropa, organizando toda la intendencia de su división en la Batalla del Ebro y trabajando al lado de personalidades militares de la talla de Vicente Rojo Lluch, Modesto Guilloto, Enrique Líster, o Manuel Tagüeña.

Con todo, a finales de diciembre de 1938 el Ejército Popular inició la retirada. El día 29 de ese mismo mes la superioridad de las tropas franquistas en la zona del Ebro se acrecentó de una manera considerable, ya que entraron en combate cinco divisiones del Cuerpo Marroquí, con lo que el Cuerpo del Ejército de la Teniente tenía en frente una masa de diez Divisiones enemigas. Fue entonces cuando Modesto Guilloto ordenó el repliegue hacia la retaguardia. Este período fue el más difícil, el más agotador y el de mayor heroísmo de las tropas republicanas, puesto que los efectivos disminuían paulatina e inexorablemente. La teniente Remedios, junto con la tropa, abandonaba para siempre la comarca de El Priorat. Sin embargo, a mediados de febrero de 1939 y en plena retirada, Modesto Guilloto intentó una reorganización del ejército del Ebro para la defensa de Gerona. Fue entonces cuando repartió la 3 División entre la 42 y la 43, y es aquí precisamente donde se pierde el rastro de la heroína, pues no se ha podido averiguar a cual de estas dos Divisiones fue asignada.

El ejército del Ebro cruzaría la frontera francesa entre los días 8 y 9 de febrero de 1939; en Banyuls se concentraron todos los militares pertenecientes a los Estados Mayores del V y del XV Cuerpo del Ejército. El grueso de la tropa en lugar de ser agrupado en campamentos militares provisionales hasta su nueva salida hacia España como había prometido por el Gobierno de la República- se encontró de hecho recluido en diversos campos de concentración. Negrín había indicado la salida de los Mandos del ejército del Ebro para España y así lo hicieron todos los altos mandos, los jefes de Cuerpo, así como los comisarios de División. Esta expedición estaría bajo las órdenes del Ministro de Defensa, aunque los preparativos de la sublevación Casadista ya estaban en gestación (Modesto Guilloto, 1978). 


\section{El exilio permanente (1939-1985)}

La teniente Remedios Jover no se incluyó en la expedición militar solicitada por el Ministerio de Defensa. Actualmente no podemos verificar si fue por decisión propia (como haría el General Vicente Rojo Lluch) o simplemente por el hecho de ser mujer. Si bien la Constitución había recogido bastantes contenidos de igualdad entre hombres y mujeres, muchos se quedaron sólo en principios genéricos. La desigualdad se mantuvo en muchas esferas, como la de que permanecieran cerrados a las mujeres los cuerpos estatales del Ejército o la Policía (Nuñez, 1998). Por ello, cabría preguntarse si fue decisión de la propia Teniente el hecho de quedarse en el campo de concentración de Argelés Plage, o bien consecuencia del olvido y abandono expreso por parte del ejército republicano y por extensión de la República, Gobierno por el que ella había luchado tan firmemente.

Tanto su hijo Ramón como su nieta Sylvie insisten en que a la teniente Remedios se le dio la oportunidad de exiliarse en Rusia o México como al resto de los mandos del Estado Mayor del Ejército del Ebro, pero que decidió quedarse en Francia para estar más cerca de sus hijos y padres (Gómez Jover, 17-02/2010). Y de hecho así fue. Remedios Jover pasó varios meses en el campo de concentración de Argelés, allí conocería al que sería su segundo marido, Tomás Gómez, un exiliado republicano que, tras conseguir un aval, trabajó en la cocina de un restaurante de Toulouse. De este matrimonio nacería una hija, Elisa, lo que implica la responsabilidad de Remedios sobre dos familias, separadas de la Teniente sentimental y geográficamente. Sin embargo Remedios se mantuvo en contacto con ambas, hasta el punto de que llegó a crearse entre ellas una estrecha relación. Ramón Aracil Jover (23-11-2009) habla cariñosamente de Elisa como "mi hermana de Francia",

La trayectoria de la Teniente en Francia queda pendiente de investigación. Aparentemente Remedios abandonó por completo la lucha social, se dedicó a trabajar sirviendo en un convento de monjas y limpiando casas. No volvería a España hasta pasados unos años de la muerte de Franco, y lo hizo para asistir a la boda de su nieta Remedios Aracil.

Aún a finales de los años setenta, la Teniente no se atrevió a quedarse en Petrer por miedo a la represión y a una posible detención. Por eso se alojaba en una casita de campo que la familia poseía en las afueras de la localidad (Aracil Alzamora, 17-042010). En la actualidad podemos decir que el temor de Remedios a posibles venganzas era completamente infundado: consultados los fondos documentales de Petrer, Elda y 
Alicante -lo calidades en las que Remedios Jover se había destacado en las huelgas de los años 30, y posteriormente, en calidad de militar durante la guerra civil-, nada nos han aportado a este respecto. Ninguno de los vecinos de estas localidades delató o encausó a la Teniente, su nombre no consta en ninguna parte. Tampoco consta en la Causa General de la ciudad de Madrid, y esto resulta cuanto menos sorprendente.

Mucho después de haber terminado la contienda, el régimen franquista continuaba buscando información que les permitiera conocer el paradero y la responsabilidad de los republicanos que de algún modo habían participado en cualquier acto que fuese considerado como de "desafecto al Glorioso Movimiento Nacional", y no sólo durante la Guerra Civil, las responsabilidades se buscaban también en el período que abarcaba al menos hasta 1934. Por lo que a nosotros nos interesa, cabe destacar el hecho de que en la Causa General de la ciudad de Madrid encontramos un modelo nuevo de persecución del vencido. Nos referimos a la información extraída a través de procedimientos judiciales militares (aunque no sumarísimos) desarrollados durante la guerra civil y ejecutados por el gobierno de la República. Se trata en principio de juicios de "deserción" realizados por el Tribunal Militar Permanente del Primer Cuerpo del Ejército Popular durante los años 1937 y 1938 a miembros de la Brigada de la teniente Remedios. Los Autos tienen fecha de 18 de abril de 1938, fallando: "sin responsabilidad de los encausados",2.

Estos "encausados" eran los soldados y oficiales que presenciaron las deserciones y fugas y por consiguiente dispararon al prófugo que resultó muerto en el frente al no detenerse cuando se le dio el alto. En sus declaraciones, todos explican los hechos de una manera coincidente: “el soldado intentó saltar la alambrada, se le dio el alto y al no responder se le disparó causándole la muerte" "era de noche y se hallaba en la línea que separa nuestra posición de la del enemigo, se le dio el alto pero no contesto",

A partir de 1943, todos los encausados serían detenidos por la justicia franquista, e interrogados por lo sucedido en la Sierra de Guadarrama con los desertores. Se les acusan de asesinato de personas afectas al régimen, católicas y de derechas.

Algunos de ellos se encontraban encarcelados en esos momentos, pero otros, simples soldados rasos que habían sido miembros de la $30 \mathrm{BM}$, se hallaban viviendo y trabajando en sus respectivas localidades. Sorprende las declaraciones que realizan

${ }^{2}$ FC_Causa_General, 1521, Exp. 31 y 34. Pieza 2, Tomo XXII. Ramo 53, Ejército Rojo. 30 Brigada Mixta (PARES, Centro Documental de la Memoria Histórica).

${ }^{3}$ Ibíd., Nota 2. 
ahora, que nada corresponden con las prestadas en 1938, lo que indica que fueron realizadas bajo tortura o presión. En estas declaraciones ya no se habla de fuga/deserción, sino de viles asesinatos realizados en los mismos parapetos, en las trincheras o chabolas, a sangre fría, sin motivos aparentes ni justificación alguna.

Los soldados rasos acusan a los oficiales de asesinos encubiertos por grado militar que ostentaban en ese momento, “crueles y sin escrúpulos...". ${ }^{4}$ En marzo de 1945 se llegó a inculpar al comandante del 117 Batallón Ismael Bueso Vela de estar implicado en el asesinato de José Calvo Sotelo, ya que era Guardia de Asalto en ese momento, batallón que por lo demás es en el que cumplía con sus tareas militares la teniente Remedios. Casi todos los detenidos son de la zona alicantina de Petrer, Elda y Novelda, aunque también los hay de Madrid capital o de Murcia. Sus edades oscilan entre los 25 y 27 años por lo que en la fecha de los Autos no tendrían más de 18 o 20 años. En su mayoría fueron voluntarios y afiliados a la UGT. Permanecieron en la sierra de Guadarrama hasta finales de 1938, después unos irían a Extremadura y otros al levante peninsular hasta el final de la contienda.

De las declaraciones de los detenidos obtuvieron todos los nombres de los jefes, oficiales, suboficiales, comisarios, secretarios, enlaces, delegados políticos de la Brigada Mixta de la teniente Remedios y de soldados rasos. Cuando el interrogado no sabía el nombre, indicaba el apodo del compañero “el Cabezo, el Bombín, el Negro". Alguno incluso describe paso a paso el intento de la toma de Cabeza Lijar en 1936, lugar donde -como ya hemos explicado- fue herida y dada por muerta Remedios Jover. No obstante, el nombre de la Teniente no aparece en ningún documento. Sus compañeros no la delataron, es como si no hubiera existido jamás. ¿Qué motiva a un hombre soldado a no hablar de una mujer también soldado a pesar de estar bajo una fuerte presión? Difícil respuesta sin lugar a dudas.

Como explica Reig Tapia (1999), toda la historia contemporánea de España está marcada por la guerra civil. A la barbarie de los tres años de la contienda, hay que añadir cuarenta años de absoluta represión sustentada por el terror institucionalizado. Acontecimientos tan violentos y devastadores como una guerra civil tienden a producir en los seres humanos experiencias traumáticas de una complejidad y gravedad extraordinarias. La experiencia del combate produce problemas de salud física y mental a corto plazo, ya que entre doscientos y cuatrocientos días en los frentes de guerra son suficientes para derrotar psicológicamente incluso al soldado más fuerte. Entre un 30-35

\footnotetext{
${ }^{4}$ FC_Causa_General, 1521, Exp. 31 y 34. Pieza 2, Tomo XXII. Ramo 53, Ejército Rojo. 30 Brigada Mixta (PARES, Centro Documental de la Memoria Histórica).
} 
$\%$ de los soldados españoles padeció estrés de combate que a su vez, y en un número igualmente importante, acabó produciendo el síndrome de estrés postraumático o TEPT.

Una de las variantes del estrés de combate alude al diagnóstico de una forma gravísima de añoranza llamada nostalgia. Se da sobre todo en soldados jóvenes con pensamientos obsesivos sobre su hogar, que muestra además una apatía extrema, pérdida de apetito, diarrea y fiebre (Ruíz Vargas, 2006). Si seguimos el testimonio de Mika Etchebehere (Mika Feldman), que en noviembre de 1936 era capitán de la Columna Motorizada del POUM (después 38 Brigada Mixta), podremos entender el papel que las mujeres soldado con cargo militar del Ejército de la República ejercieron sobre la tropa. Así como el contenido de la poesía dedicada a la Teniente Remedios por parte del soldado Fernando Verdú con motivo del traslado de ésta a la 3 División, Verdú escribe en 1937:

"Tú que para nosotros has sido la madre de nuestros corazones [...] Tú que nos amas como a hijos [...] Remedios. ¡Salud!, de ti me despido colmándote de honores porque para nosotros has sido una de nuestras madres mejores".

En sus memorias Mika responde de algún modo al concepto de "madre" que los soldados parecen tener respecto a las mujeres con cargo militar. Ella misma se preguntaba cuál era el lazo invisible que la unía a los milicianos teniendo en cuenta que era una mujer y la respuesta: "Yo les protejo y ellos me protegen son mis hijos y a la vez mi padre, se preocupan por lo poco que como y lo poco que duermo, encontrando milagroso que resista tanto o más que ellos..." (Etchebehere, 1976:192).

Mika se descubre a ella misma como “[...] Capitán madre de familia que vela por sus niños soldado, incluso si tienen el cabello gris" (Ibíd., p. 206).

Tanto la poesía de Verdú como el testimonio de Mika pueden arrojar un halo de luz a la pregunta indicada más arriba de porqué los soldados de la 30 Brigada Mixta no delataron a la Teniente Remedios en 1943 tras ser detenidos e interrogados por las autoridades franquistas. La respuesta parece estar en que la guerra se alargaba por momentos, la mayoría de los soldados venían de las Milicias Voluntarias, por lo que no estaban entrenados para resistir mucho tiempo en primera línea de fuego, y el síndrome de "estrés de combate" empezaba a hacer mella entre la tropa.

Los soldados en su imaginario parece que sustituyeron los galones militares de la Teniente (y de Mika), por el concepto de "madre", estableciendo un comportamiento psicoafectivo peculiar: la madre protege y ama, por lo tanto hay que protegerla y amarla. Delatar a la Teniente implicaba de algún modo una doble "traición", por un lado quebrantar la lealtad afectiva hacia la "madre", pero por el lado puramente militar 
suponía un atentado moral contra el "honor" del Ejército Popular. Ello nos lleva hacia otro derrotero, el estrictamente militar y el problema que suscitó entre la tropa el hecho de tener en sus filas a mujeres soldados con o sin cargos militares.

El espíritu castrense reinante sobre todo después de la Primera Guerra Mundial aludía a que el buen soldado debía sentirse glorificado en la batalla, no debía mostrar emoción alguna y no podía sucumbir al miedo, de modo que, ante un soldado que presentase "neurosis de guerra" se le sometía a Consejo de Guerra y era por consiguiente deshonrado y expulsado del Ejército (Ruíz Vargas, 2006). Este espíritu castrense se encontraba también entre la tropa del Ejército Popular español, un hombre no podía tener miedo en las trincheras, y menos si su compañero de armas era una mujer. Volvamos por un momento a la poesía de Verdú (1937): “Tu, cuando más cruenta la lucha, has ido y has alentado nuestros corazones, no has reparado en peligro ¡Lo que no han hecho muchos hombres!”.

El problema del miedo o cobardía de los soldados y su empeño en disimularlo ante la compañera de armas fue descrito ya en 1936 por Pablo de la Torriente Brau en su obra "Cartas y Crónicas de España" (De la Torriente Braun, 2002). Pablo fue corresponsal de guerra y comisario político de la Primera Brigada de Choque al mando de Valentín González "el Campesino” a principios de noviembre del 36, poco antes de morir en Majadahonda. Estuvo en el frente de Guadarrama (el mismo donde se hallaba la teniente Remedios), durante tres meses taquigrafiando el día a día en las trincheras.

A inicios de octubre de 1936 la miliciana Dolores Maiquez, soldado de la Tercera Compañía de Acero, estando destacada en un parapeto en la Peña del Alemán, recibió un tiro de fusil y fue herida de muerte. Todo parece indicar que Dolores cayó por imprudente (o demasiada valentía), porque de su parapeto había cruzado al vecino para buscar unos gemelos y en ese instante fue interceptada por las balas enemigas. Las palabras que dirige entonces el teniente A. Ruíz a sus subordinados demuestran que el disimulo del miedo ante una compañera de armas fue un grave problema:

[...] un muerto no es sólo un compañero que cae. Es un rifle menos para matar fascistas. Ustedes tienen miedo. Tienen miedo a que los demás se crean que tienen miedo. Y hay que acabar con esto. Y no hay que ser más valientes porque haya mujeres. Aquí las mujeres son hombres. Porque aquí sólo hay rifles de la revolución. Aquí no hay sexos. Y del parapeto no se sale sino cuando es imprescindible (Citado por Torriente Brau, 2002: 98).

Torriente Brau también describe cómo el teniente de la Guardia Civil Paco Galán (hermano del capitán Fermín Galán, fusilado en Jaca en 1930), al mando de la Columna Galán en la Sierra de Guadarrama, se refería al tema de la mujer en el Ejército 
y a la mentira de la desigualdad que desaparecía ante el rifle. Por su parte, el comandante Valentín González, aunque no le gustaba tener a muchas mujeres en sus filas, de las que tenía decía que eran "milicianos". Recordemos que el periódico "Octubre" en agosto de 1936 hacía alusión al valor de Remedios Jover: "Su valor es digno de que figure en nuestro Cuadro de Honor" (Navarro Poveda, 1997:30). Poco después el comandante Manuel Tagüeña decía del comportamiento de la Teniente durante la batalla: "Interviniendo con arrojo en el combate librado en la posición de Cabeza Lijar" (Tagüeña Lacorte, 1936).

En 1937, ante el traslado de Remedios a la 3 División, el soldado Fernando Verdú (1937) decía: “de ti me despido colmándote de Honores”. El Honor es una cualidad moral que está presente en la figura de la teniente Remedios ya que, como hemos visto, le lleva al cumplimiento de los propios deberes respecto al prójimo (civiles y soldados) y respecto a ella misma.

Finalmente, cabe mencionar que Remedios nunca habló de su pertenencia al Ejército Popular ni tan siquiera con los más cercanos de su familia, por lo que jamás sabremos si ella se desenvolvía entre la tropa como "Madre" tal y como la veían los soldados, o bien como "Militar" con cargo, que de hecho es la tarea que desempeñó dentro del Ejército: "Mujer disciplinaria", "a veces despótica" o "de difícil carácter para con la tropa", son algunos de los adjetivos que los testimonios nos han dado respecto a la personalidad de la Teniente, lo que demuestra que el espíritu castrense estaba presente en su persona. Defensora del gobierno republicano y de las libertades conseguidas democráticamente en España, es sin lugar a dudas heroína de la República y víctima del franquismo como también los son sus hijos y su familia. La teniente Remedios Jover Cánovas, miembro activo del Estado Mayor de la 3 División del XV Cuerpo del Ejército murió en His (Francia) en 1985, sin que, a fechas de hoy, el gobierno democrático de España haya reconocido su valiosa aportación personal en la defensa de las libertades de los españoles. 


\section{BIBLIOGRAFÍA}

- Casanova, J. y Gil Andrés, C. (2010): Historia de España en el siglo XX. Barcelona: Ariel.

- Cuéllar, J. (2006): L'epíleg del Front d'Aragó. Barcelona: 62.

- De la Torriente Brau, P. (2002): Cartas y Crónicas de España. La Habana: La Memoria.

- Engel, C. (2005): Historia de las Brigadas Mixtas del Ejército Popular de la República (1936-1939). Madrid: Almena.

- Etchebehere, M. (1976): Mi guerra de España. Barcelona: Plaza \& Janes.

- Henríquez Caubín, J. (1944): La Batalla del Ebro. Maniobra de una División. México: Unda y García.

- La Gaceta de Madrid (1936), septiembre-noviembre.

- La Gaceta de la República (1936), diciembre.

- Martínez López, M. (2007): La experiencia republicana y la guerra civil en Alicante. Alicante: Club Universitario San Vicente.

- Martínez Maestre, J. R. (1990): La fábrica de lonas de Santa Bárbara. En El Carrer, Petrer.

- Modesto Guilloto, J. (1978): Soy del Quinto Regimiento. Notas de la Guerra de España. Barcelona: Laia.

- Navarro Poveda, B. (1997): Mujeres de Petrer en la II República. En Festa, Ayuntamiento de Petrer.

- Núñez, M. G. (1998): "Políticas de igualdad entre varones y mujeres en la II República española". En Espacio Tiempo y Forma Serie V. Historia Contemporánea, tomo. 11, pp. [en 393-445 línea] Disponibel en: http://espacio.uned.es:8080/fedora/get/bibliuned:ETFSerie5-625F5B8D-3D2A-2F0F-6FE4B2EF6201352C/PDF [16/02/2011].

- Ponce Lorenzo, F. (1997): Patología asociada a la industria del calzado. En Festa, Ayuntamiento de Petrer.

- Reig Tapia, A. (1999): Memoria de la Guerra Civil. Madrid: Alianza.

- Rico, L. (2007): Caseros. Ramón Jover y Remedios Cánovas. En El Carrer, Petrer.

- Ruíz Franco, M. R. (2000): “Transformaciones, pervivencias y estados de opinión en la situación jurídica y social de las mujeres en España (1931-1939)". En Historia y Comunicación Social, nº 5, pp. 229-254 [en línea] Disponible en: http://revistas.ucm.es/ inf/11370734/articulos/HICS0000110229A.PDF [04/02/2011]. 
- Ruíz Vargas, J. M. (2006): “Trauma y Memoria de la Guerra Civil y de la dictadura franquista". En Hispania Nova [en línea] Disponible en: http://hispanianova.rediris.es/6/ dossier/ 6d012.PDF [12/02/2011].

- Strobl, I. (1996): Partisanas. La mujer en la resistencia armada contra el fascismo y la ocupación alemana (1936-1945). Barcelona: Virus.

- Tagüeña Lacorte, M. (2005): Testimonio de dos Guerras. Barcelona: Planeta.

\section{Documentación y archivos:}

- Archivo familiar Aracil-Jover.

- Mezquita Moreno (1937): “Certificado médico original emitido por el doctor Mezquita Moreno”, 14/08/1937, archivo familiar Aracil-Jover.

- Tagüeña Lacorte (1936) "Baja oficial como soldado del Ejercito Republicano de Remedios emitida por el Colonel Tagúeña”, 31-12-1936, archivo familiar Aracil-Jover.

- Archivo Municipal de La Morera del Montsant.

- Archivo Municipal de La Vilella Alta.

- Correspondencia privada Constantino Pascual Payá.

- Centro Documental de la Memoria Histórica.

\section{Fuentes Orales:}

- Aracil Alzamora, Remedios [Comunicación personal] Petrer, 17-4-2010.

- Aracil Jover, Ramón [Comunicación personal] Petrer, 23-11-2009.

- Aracil Redondo, Pilar [Comunicación personal] Petrer, 17-4-2010.

- Beltrán, Encarnación [Comunicación personal] La Vilella Alta, 15-9-2009.

- Francés, Faustino (alias “Gregorio”) [Comunicación personal] Petrer, 6-5-2010.

- Gómez Jover, Sylvie [Comunicación personal] Petrer, 17-2-2010.

- Medina Beltrán, Pepe [Comunicación personal] 30-11-2009.

- Ossó, Josep María [Comunicación personal] Vallirana, 9-6-2010.

- Salat, Pepita [Comunicación personal] La Vilella Alta, 23-9-2006.

- Sentís, Rodrigo [Comunicación personal] La Vilella Alta, 20-9-2006. 